\title{
Food-Cobalamin Malabsorption: A Controversial Etiology of Symptomatic Vitamin B12 Deficiency
}

\author{
Emmanuel Andres ${ }^{1^{*}}$, Thomas Vogel ${ }^{2}$ and Pierre Olivier Lang ${ }^{3}$ \\ ${ }^{1}$ Service Médecine Interne, Diabète et Maladies métaboliques, Clinique Médicale B, Hôpitaux Universitaires de Strasbourg, 67000 Strasbourg, France \\ ${ }^{2}$ Service Médecine Interne et Gériatrie, Hôpital de la Robertsau, Hôpitaux Universitaires de Strasbourg, 67000 Strasbourg, France \\ ${ }^{3}$ Service de Gériatrie et de Réadaptation gériatrique, Centre Hospitalier Universitaire Vaudois, CH-1011 Lausanne, Suisse, France
}

*Corresponding author: Emmanuel Andres, Professor, Service de Médecine Interne, Diabète et Maladies Métaboliques, Clinique Médicale B, Hôpital Civil - Hôpitaux Universitaires de Strasbourg, 1 porte de l'Hôpital, 67091 Strasbourg Cedex, France, Tel: (33)-(0)3-88-11-50-66; Fax: (33)-(0)3-88-11-62-62; E-mail: emmanuel.andres@chru-strasbourg.fr

Received date: Aug 26 2015, Accepted date: Aug 27, 2015, Publication date: Aug 31, 2015

Copyright: (C) 2015 Andres E, et al. This is an open-access article distributed under the terms of the Creative Commons Attribution License, which permits unrestricted use, distribution, and reproduction in any medium, provided the original author and source are credited.

\section{Opinion}

Until the 1990s, the main causes of cobalamin (vitamin B12) deficiency in adults are Biermer's (also called Addison' disease or pernicious anemia) and malabsorptions [1]. Thanks to progress made during the last 15 years in the understanding of cobalamin metabolism, new physiopathological concepts have emerged, including a new medical concept: the "food-cobalamin malabsorption" [2]. This new clinical syndrome was found to be the leading cause of symptomatic cobalamin deficiency in a number of recently published series [3-5]. However, controversies persist in the scientific literature about his real involvement in severe cobalamin deficiency. In fact, some clinicians believe that this disorder is responsible only on "subtle" B12 deficiency [6]. In this editorial, we sought to detail our personal perception and experience of this food-cobalamin malabsorption in clinical practice.

Food-cobalamin malabsorption is a medical disorder characterized by the inability to release cobalamin from food or its carrier proteins [7]. Cobalamin is found exclusively in food, and daily intake requirements range from 2 to $5 \mu \mathrm{g}$ [8]. The dissociation of vitamin B12 from food or its carrier proteins and its release as "unbound" cobalamin are essential prerequisites for its binding to intrinsic factor and in fine its intestinal absorption, through the cubulin receptor [2]. Thus to our opinion, the syndrome of food-cobalamin malabsorption refers in clinical practice to all vitamin B12 deficiencies that are related to pre-absorption steps of cobalamin ("maldigestion" not "malabsorption") [8].

The Table 1 summarizes the main characteristics of the foodcobalamin malabsorption $[4,8]$. This syndrome was described by Carmel and Dawson in the 1990s [7,8]. In some cobalamin-deficient patients, these authors observed conflicting results when employing a "modified" Schilling test, which uses radioactive cobalamin bound to altered animal proteins (e.g., egg yolk, chicken, salmon), and the normal Schilling, which uses free radioactive vitamin B12 (unbound) [7]. The original description was made by Doscherholmen et al. in 1973, but was not pursued [9]. However, to date, Schilling test or its variant (modified Schilling), the gold standard to establish the diagnosis, were not available in clinical practice. Thus to our opinion, food-cobalamin malabsorption nowadays is a diagnosis of exclusion [8].

As illustrated in the Table 1, several causes of cobalamin malabsorption have been reported, the most common being age, atrophic gastritis, Helicobacter pylori infections, and the intake of proton pump inhibitors, H2-receptor antagonists, or metformin $[4,7,8]$. In an American study including 202 subjects, Latino-American or Afro-American race, advanced age, and $H$. pylori infection were shown to be independent risk factors for FCM. Some studies revealed a female preponderance, though this still needs to be confirmed [10].

\begin{tabular}{|c|c|}
\hline \multicolumn{2}{|r|}{ Diagnostic criteria for food-cobalamin malabsorption syndrome } \\
\hline 1. & Serum cobalamin levels $<200 \mathrm{pg} / \mathrm{ml}$ \\
\hline & $\begin{array}{l}\text { Normal "standard" Schilling test (using free cyanocobalamin labelled with cobalt-58) or abnormal "modified" Schilling test (using protein-bound radioactive } \\
\text { lamin) } \ddagger\end{array}$ \\
\hline 3. & No dietary cobalamin deficiency (intake $>2 \mu \mathrm{g}$ per day) \\
\hline 4. & Associated causes: \\
\hline- & Atrophic gastritis, chronic $H$. pylori infection, gastrectomy, gastric by-pass \\
\hline- & Exocrine pancreatic insufficiency (alcohol abuse...) \\
\hline- & Chronic alcohol abuse \\
\hline- & Intake of antacids (H2-receptor antagonists or proton pump inhibitors) or biguanides (metformin) \\
\hline- & Microbial overgrowth, AIDS \\
\hline- & Sjögren's syndrome, scleroderma \\
\hline
\end{tabular}


Table 1: Characteristics of food-cobalamin malabsorption syndrome according to Andrès et al. [4,8]†.

In our experience, the clinical manifestations of food-cobalamin malabsorption are not very different from those of cobalamin deficiencies associated with other causes, e.g. Biermer's disease $[8,11]$. However, it should be emphasized that Carmel first believed that foodcobalamin malabsorption was associated with moderate cobalamin deficiency, leading to only "subtle" clinical symptoms ("subtle cobalamin deficiency") [6]. Our published data contradicts this assertion, as illustrated in Table $2[4,12]$. It is to note that Schilling test was used in the majority of our patients, with normal results of this test (with and with administration of intrinsic factor). The classic hematological abnormalities encountered include aregenerative macrocytary anemia and other less common, though more severe, hematological abnormalities as: intramedullar hemolysis, thrombopenic purpura, myelodysplasia, medullar aplasia, early-stage pseudo-leucosis, or pseudo-thrombotic microangiopathy [4,12]. Neuropsychiatric abnormalities are also common clinical manifestations of the food-cobalamin malabsorption, and may occur even if hematological abnormalities do not develop. Combined scleroses of the spinal cord, peripheral neuropathies, or cognitive dysfunctions are frequent manifestations [4,12]. Besides the aforementioned manifestations, those related to the age of the patient or the etiology of malabsorption should also be considered.

\begin{tabular}{|l|l|}
\hline \multicolumn{2}{|l|}{ Clinical features of food-cobalamin malabsorption syndrome } \\
\hline $\begin{array}{l}\text { Mean age } \\
\text { years }\end{array}$ & $76 \pm 8$ \\
\hline Sex ratio (women/men) & 2 \\
\hline Symptomatic patients & \\
\hline Clinically & $70 \%$ \\
\hline Biologically & $76 \%$ \\
\hline Main clinical manifestations & \\
\hline Sensitive polyneuropathy & $45 \%$ \\
\hline Cognitive disorders & $23 \%$ \\
\hline Asthenia & $21 \%$ \\
\hline Main biological manifestations & \\
\hline Macrocytosis & $53 \%$ \\
\hline Anaemia & $21 \%$ \\
\hline Leucopenia & $11 \%$ \\
\hline Thrombocytopenia & $9 \%$ \\
\hline Pancytopenia & $6.50 \%$ \\
\hline
\end{tabular}

Table 2: Profile of 92 patients with cobalamin deficiency secondary to food-cobalamin malabsorption syndrome $[4,12]$.
According to our own experience, the prevalence of cobalamin deficiency among hospitalized patients approaches 5\%, with foodcobalamin malabsorption accounting for $50 \%$ to $60 \%$ of cases (in a population of quiet elderly patients) [8]. Thus, we believe that foodcobalamin is one of the main etiologies of symptomatic cobalamin deficiency in adult patient.

In this situation, we have documented the usefulness of oral cobalamin therapy $[13,14]$. Since 1995, numerous clinical trials confirmed the non-inferiority of the oral route (with cyanocoabalamin between 125 to $1000 \mu \mathrm{g}$ per day) as compared to the parental route in the treatment of food-cobalamin malabsorption, as evidenced by a normalization of hematological abnormalities and regression of clinical symptoms, particularly neuropsychiatric manifestations, in the majority of patients $[15,16]$. In a study, Kaptan et al. also showed that $H$. pylori eradication was sufficient to correct cobalamin deficiency [17].

\section{Acknowledgments}

To professors Marc Imler and Jean-Louis Schlienger, who initiated the first research program on vitamin B12 in Strasbourg; to the clinicians who allowed the realization of the clinical studies (CARE B12); and to the French Foundation for its support via the Robert Prize of 2004 and Jacqueline Zittoun, thanks to her knowledge of anemia and vitamin B12 and folic acid metabolic abnormalities.

\section{References}

1. Shipton MJ, Thachil J (2015) Vitamin B12 deficiency - A 21st century perspective . Clin Med 15: 145-150.

2. Dali-Youcef N, Andrès E (2009) An update on cobalamin deficiency in adults. QJM 102: 17-28.

3. van Asselt DZ, Blom HJ, Zuiderent R, Wevers RA, Jakobs C, et al. (2000) Clinical significance of low cobalamin levels in older hospital patients. Neth J Med 57: 41-49.

4. Andrès E, Perrin AE, Demangeat C, Kurtz JE, Vinzio S, et al. (2003) The syndrome of food-cobalamin malabsorption revisited in a department of internal medicine. A monocentric cohort study of 80 patients. Eur J Intern Med 14: 221-226.

5. Couderc AL, Camalet J, Schneider S, Turpin JM, Bereder I, et al. (2015) Cobalamin deficiency in the elderly: aetiology and management: a study of 125 patients in a geriatric hospital. J Nutr Health Aging 19: 234-239.

6. Carmel R (2013) Diagnosis and management of clinical and subclinical cobalamin deficiencies: why controversies persist in the age of sensitive metabolic testing. Biochimie 95: 1047-1055.

7. Carmel R (1995) Malabsorption of food cobalamin. Baillieres Clin Haematol 8: 639-655.

8. Andrès E, Loukili NH, Noel E, Kaltenbach G, Abdelgheni MB, et al. (2004) Vitamin B12 (cobalamin) deficiency in elderly patients. CMAJ 171: 251-259.

9. Doscherholmen A, Swaim WR (1973) Impaired assimilation of egg Co 57 vitamin B 12 in patients with hypochlorhydria and achlorhydria and after gastric resection. Gastroenterology 64: 913-919. 
Citation: Andres E, Vogel T, Lang PO (2015) Food-Cobalamin Malabsorption: A Controversial Etiology of Symptomatic Vitamin B12 Deficiency. J Blood Disord Transfus 6: 301. doi:10.4172/2155-9864.1000301

Page 3 of 3

10. Carmel R, Aurangzeb I, Qian D (2001) Associations of food-cobalamin malabsorption with ethnic origin, age, Helicobacter pylori infection, and serum markers of gastritis. Am J Gastroenterol 96: 63-70.

11. Pruthi RK, Tefferi A (1994) Pernicious anemia revisited. Mayo Clin Proc 69: 144-150.

12. Andrès E, Affenberger S, Vinzio S, Kurtz JE, Noel E, et al. (2005) Foodcobalamin malabsorption in elderly patients: clinical manifestations and treatment. Am J Med 118: 1154-1159.

13. Andrès E, Fothergill H, Mecili M (2010) Efficacy of oral cobalamin (vitamin B12) therapy. Expert Opin Pharmacother 11: 249-256.

14. Lane LA, Rojas-Fernandez C (2002) Treatment of vitamin b(12)-deficiency anemia: oral versus parenteral therapy. Ann Pharmacother 36: 1268-1272.
15. Andrès E, Kaltenbach G, Noel E, Noblet-Dick M, Perrin AE, et al. (2003) Efficacy of short-term oral cobalamin therapy for the treatment of cobalamin deficiencies related to food-cobalamin malabsorption: a study of 30 patients. Clin Lab Haematol 25: 161-166.

16. Andrès E, Kurtz JE, Perrin AE, Maloisel F, Demangeat C, et al. (2001) Oral cobalamin therapy for the treatment of patients with food-cobalamin malabsorption. Am J Med 111: 126-129.

17. Kaptan K, Beyan C, Ural AU, Cetin T, Avcu F, et al. (2000) Helicobacter pylori--is it a novel causative agent in Vitamin B12 deficiency? Arch Intern Med 160: 1349-1353. 